\title{
Patient Perception about Generic vs. Branded Medicines Prescribed in a Tertiary Care Hospital in Northern India -A Descriptive Study
}

\author{
Shailesh Tripathi, Sudip Bhattacharya \\ Visiting Faculty, Lucknow University, Resident, PGIMER, Chandigarh, INDIA.
}

\begin{abstract}
Background:The concept of generic prescription is widely accepted in various parts of the world. Nevertheless, it has failed to gain popularity in India due to factors such as non-availability and distrust on the product quality. However, since 2012, the Government of India, has initiated exclusive generic drug outlets called Jan Aushadhi stores. This study was undertaken to evaluate the experience and attitude of patients who were consuming generic drugs purchased from these stores. Materials and Methods: It was a questionnaire-based cross-sectional study where we have interviewed total 100 patients consuming generic and branded drugs, respectively. The perceived effectiveness, cost of therapy, quality of drugs was asked. Results: In our study $72 \%$ participants heard about generic medicines and $65 \%$ knew the difference between generic and branded medicines. $67 \%$ agreed that generic medicines are cheaper than branded medicines but only $35 \%$ of them preferred to buy generic medicines. Most (64\%) of the patients never asked his/her doctor or pharmacist (59\%) to prescribe/ distribute generic medicines. Majority of them $(61 \%)$ believed that generic medicines have lower quality than branded medicines. According to patients, $45 \%$ responded that doctors preferred branded medicines over generic medicines. In this hospital, $37 \%$ patients were prescribed generic medicines. Most of them (67\%) did not become aware of the government rules about prescribing generic medicines. Only $24 \%$ responded that government should promote generic medicines. According to $13 \%$ of patients suggest that there should be more generic medicine shops present in the hospital. Interestingly, $45 \%$ of them suggested that generic medicines should be available in all medicine shops. Conclusion: Our findings suggest that knowledge and attitude about generic medicines among participants were poor. Some of them had wrong information, which is not a good sign for implementation and sustainability of Jan Aushadhi scheme in government hospitals.
\end{abstract}

Key words: Branded drug, Cost of therapy, Generic prescription, Health policy.

\section{INTRODUCTION}

Generic medicine is identical or bioequivalence to an innovator or product brand name drug in dosage, form, safety, strength, route of administration, quality, performance, characteristics and intended use. ${ }^{1}$ On expiration of the originator product's patent term, other manufacturing companies usually appeal to the drug regulatory bodies for approval to market the generic versions of the originator drugs. Generic medicines are sold under the non-propriety name or branded name. Another term is frequently used in the pharmaceutical industry that is branded generic medicines. It is called so because the combination of the manufacturer name and the non-propriety name is used for marketing the drug molecule. Usually the branded medicine cost higher than generic medicines. While manufacturing the generic medicines, the drug companies used the same active ingredients and shown to exert its pharmacological action as well as adverse effect and being it is as their brand name counterpart. Also, generic medicines have the same quality, strength, purity and stability as brand-name medicines (as it is bioequivalent to innovate compound) and work in the same way and in the same amount of time branded medicines. New medicines are developed under price protection. $^{2}$
DOI: 10.5530/ijopp.11.2.19

Address for correspondence: Dr. Sudip Bhattacharya. MD. PGIMER, Chandigarh, India. 160012

Phone no: 8872397091

Email Id: docbilu@gmail.com

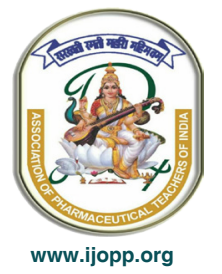


The use of generic medicines is rapidly increasing globally because of economic pressure on medicine budgets in the form of out of pocket expenditures (OOP). Generic medicines provide the opportunity for significant savings in healthcare expenditure since they are usually substantially lower in price than the innovator brands. Generic medicines are cheaper than branded medicines. However, Physicians' are apprehensive regarding the quality of generic medicinesand have concerns about their reliability. Marketing practices adopted by manufacturers of imported branded medicines also propagate the belief that generics are of inferior quality as reported from countries in central and eastern Europe, USA and in the Soviet Union. ${ }^{3}$

Currently, almost all medicines in India are sold under a brand or trade name and medicines are called as branded medicines or branded generic. In India, many pharmaceutical companies manufacturing two types of products for the same molecule, i.e. the branded product which they advertised and push through doctors and branded generic which they expect retailers to push in the market. The so-called branded medicines in India are manufactured and promoted by multinationals (MNCs) or by reputed Indian manufacturers while branded generics, on the other hand, are not promoted or advertised by the manufacturer. Quality and safety issues always matter of concern with the substitution of branded medicines with generic. The U.S. Food and Drug Administration (FDA) examine generic formulations and approve them as bioequivalent to brand-name drugs in safety, strength, and quality (Nightingale SL, 1998) and similar responsibility lies on the Drug Control Authority of India. ${ }^{4}$

Our country has become competent enough to produce quality branded and generic medicines. Pharmaceutical industry becomes a giant compared to any other industry. Data suggests that pharma industry increased to 1,19,000 crores in 2012 from 1,500 crores in 1980. However, these medicines are reasonably priced, as compared to the developed countries. Still, a large population which belongs to a marginalised category in our country cannot afford these branded medicines. Accordingly, 'ensuring availability of quality medicines at affordable prices to all, has been a key objective of the Indian government.

To address the problem some of the essential steps taken to enable this are:
1. Price control of Scheduled Drugs through the National Pharmaceutical pricing authority (NPPA)
2. Price regulation of Non-Scheduled Drugs
3. Uniform VAT of $4 \%$ on medicines
4. Reduction in excise duty from $16 \%$ to $4 \%$.

In addition to thatfor the more impoverished masses, the government has launched a countrywide Jan Aushadhi Campaign. ${ }^{5}$

Despite increment in government's health budget over the last 25 years, there has been no relief on sharply rising medical costs in the country. Despite considerable growth in the pharmaceutical sector, availability and affordability of essential medicines continue to be an essential issue for the healthcare providers in India. There is a long debate continuing regarding the effectiveness of generic medicines despite the government has taken initiatives for promoting generic medicines. ${ }^{6}$ It is high time to examine the perception of such good initiatives taken by the government of India. This is very pertinent in tandem with government's initiative to evaluate the patient's perception level regarding generic medicines vs branded medicines. For this reason, we intended to conduct this pilot study.

\section{METHODOLOGY}

Our objective was to evaluate the patient perception about generic and branded medicines prescribed in a tertiary care hospital. It was a cross-sectional study, and the study duration was eight months. The study was conducted in the OPD with a sample size of 100 (10\% of total sample size-1000). We used a convenient sampling method. The patients were interviewed with a pretested simple questionnaire about their perception about generic and branded medicines. Besides demographic and biological data, it included questions addressing knowledge (difference between generic and branded medicines), attitude (attitude for buying generic medicines over branded medicines) and practice of taking generic medicines (asking doctor or pharmacist to prescribe generic medicines etc.) The responses were categorised into two to three variables wherever applicable. Descriptive statistical analyses were performed using SPSS software package version 16.

Ethical clearance was taken from Institute ethical committee and written informed consent was taken from all interested patients/relatives. The questionnaire was translated into the vernacular language, and internal consistency came $>0.88$.

\section{RESULTS}

Demographic details of respondents are given in Table1. In our study, it was found that most of the patients (72\%) heard about generic medicines. Among all patients, $65 \%$ of them knew about the difference between generic and branded medicines. Majority (67\%) of them responded that there is a difference in price 
Table1: Demographic details of respondents.

$\begin{array}{cc}\text { Mean age } & 39.53 \pm 2 \times 14.4 \text { yrs } \\ \text { Sex } & \mathrm{N}(\%) \\ \text { Male } & 44 \\ \text { Female } & 56\end{array}$

\section{Marital status}

Married

78

Unmarried

Widowed

State

Chandigarh

Haryana

Punjab

Himachal Pradesh

Jammu and Kashmir

Education

Illiterate

Primary

Secondary

Higher secondary

Graduate

Postgraduate

Income

$<15000$

16000-20000

21000-25000

26000-30000

$>30000$

\section{1}

1

25

35

31

6

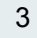

1

16

18

35

24

06

43

15

15

10

17

between those two types of medicines. According to the participants, $67 \%$ agreed that generic medicines are cheaper than branded medicines. Regarding purchasing, only 35\% responded that they preferred generic medicines. Most of the patients never asked his/her doctor $(64 \%)$ or pharmacist $(59 \%)$ to prescribe/distribute generic medicines. Nearly two-thirds of the patients believe that quality of generic medicines is different from branded one. Majority of them (61\%) believed that generic medicines have lower quality than branded medicines. According to patients, $45 \%$ responded that doctors preferred branded medicines over generic medicines. The majority (44\%) of the patients responded that chemist prefers branded medicine for selling. In this hospital, 37\% patients were prescribed generic medicines. Most of them (67\%) did not become aware of the government rules about prescribing generic medicines. As per rules, $23 \%$ responded thatdoctor should prescribe generic medicines, $47 \%$ were in favour of branded medicines, and 30\% knew that doctor could prescribe any medicine. Only 30\% responded that government promotes generic medicine.

However, 38\% were in favour of branded and 32\% were in favour of both.

Only 24\% responded that government should promote generic medicines. According to $13 \%$ of patients suggest that there should be more generic medicine shops present in the hospital so that it will benefit them. Interestingly, $45 \%$ of them suggested that generic medicines should be available in all medicine shops. They also requested that their choice should be asked for prescription by the doctors. As presently doctors did not bother about the patient's choice to purchase branded or generic medicines in all cases.

\section{DISCUSSION}

Despite encouragement from policy-makers, generic drug use in India is yet to gain widespread popularity. The practice of using generic medicines so far has remained confined mostly to limited to the government hospitals in our country. It is a well-known and undisputed fact that generic drug can benefit economically. The limited availability, poor knowledge and attitude of patients regarding quality generic formulations act as bottlenecks to the widespread adoption of generic drugs in case of prescribing and dispensing activity. ${ }^{6}$

Since 2012, Ministry of Health and Family Welfare hasimplemented the policy of "mandatory generic drug use" in government-funded hospitals.

Simultaneously, to ensure availability of generic drugs which are seldom available in the open market, the Jan Aushadhi scheme has been launched in larger public hospitals all across the state. Out of 121 proposed Jan Aushadhi store, 93 have become operational providing generic medicines at a low retail price. ${ }^{7}$ This initiative aimed to create public awareness and to increase faith to generic medicines. This prompted us to carry out a pilot study for evaluation of the experience of generic drug use among patients attending this tertiary care institute.

In this study, we observed that $67 \%$ of the patients believed that generic drugs were cheaper than branded drugs. However, only $61 \%$ respondents believed that generic medicines have lower quality than branded medicines. This finding is not encouraging at all. Similar findings were observed in a focus group interview conducted in Alabama, USA, among African American citizens, many concerns regarding the use of generic medications were questioned in a different forum. The participants perceived that generics drugs was less potent than branded ones. Many people also believed that generics are not "real"medicines. However, poor people are forced to "settle" for generics due to low treatment cost. Contrarily, in accordingly to the Finnish patients, $81 \%$ of the participants opined that low-cost 
Table 2: Patient perception about generic and branded medicines.

\section{Questions}

1. Do you ever heard about generic medicine?

2. Do you understand the difference between GENERIC and BRANDED medicine?

3. Do you know that there is price difference between GENERIC and BRANDED medicine?

4. If yes, then which is cheaper Generic?

5. Would you prefer buying Generic medicines over Branded medicines?

6. Have you ever asked your doctor to prescribe Generic medicines?

7. Have you ever asked the chemist to give you Generic medicines in place of Branded medicines?

7. a) In case of NO, why it happened so?

8. Do you think there is a difference in the quality of Generic medicine as compared to Branded variant?

$$
\text { If yes }
$$

a. Generic medicines have better quality than Branded

b. Generic medicines have lower quality than Branded medicines

c) Generic medicines have similar qualities as Branded

10. Do you think there is a difference in the price of Generic and Branded medicines?

\section{If yes}

Generic medicines have higher price than Branded medicines

Generic medicines have lower price than Branded medicines

Generic medicines have thesame price as that of Branded medicines

11. Which type of medicines do doctors prefer to prescribe you?

12. Which of the Drug Chemist prefer to sell you?

14. What type of medicines are prescribed in this hospital?

15. Which type of medicines does Indian Government promote?

16. Are you aware of any government rules regarding Generic or Branded medicines?

17. Which type of medicine name mustbe written on the patient prescription as per the Government rules?

18. Which type of the medicines whether generic or branded, do you consider should be promoted?

19. What shops do you suggest for thepromotion of Generic medicines in this hospital?

\section{Yes $(\mathrm{N}=100)$}

72

65

67

67

34

36

41

Don't had the choice

100

67

29

61

10

67

23

67

10

Generic

15

14

37

30

Yes

33

Generic

30

24

In all drug store

In selected
drug store

40

Branded
55
56
23
30
No

Branded

38

56

32

20

generic drugs to be qualitatively inferior to, or altogether different from, branded drugs. So, from the above studies, we get mixed observations.

In our study, patients attending the public hospital were socio-economically as well as educationally constrained, but they still believed that generic drugs available from Jan Aushadhi were ineffective. Most of the study participants $(67 \%)$ did not become aware of the government rules about prescribing generic medicines. As a result, 
we observed that most of the patients never asked his/her doctor $(64 \%)$ or pharmacist $(59 \%)$ to prescribe/ distribute generic medicines. It is a typical scenario in most of the public hospitals.

Regarding prescription practices of generic medicines, the participants were divided in their opinion. Nearly one-fourth of participants were responded that doctor should prescribe generic medicines, half of them were in favour of prescribing branded medicines, and one fourth knew that doctor could prescribe any medicine. These findings required serious attention to the policy makers.

Nevertheless, the results are not encouraging regarding the future of generic prescribing policy in the nation and indicate that it would be challenging to pursue its full implementation. The perceptions of patients regarding effectiveness, cost, and strict adherence to the rules needs of prescribing generic drugs were comparable to branded medicines.

\section{CONCLUSION}

Our findings suggest that knowledge and attitude about generic medicines among participants were poor. Some of them had wrong information, which is not a good sign for implementation and sustainability of Jan Aushadhi scheme in government hospitals.

\section{ACKNOWLEDGEMENT}

We acknowledge to the all patients who had participated in our study.

\section{ABBREVIATIONS}

OOP: Out of Pocket Expenditure; MNC: Multi National Company; VAT: Value Added Tax.

\section{CONFLICT OF INTEREST}

The authors declare no conflict of interest.

\section{SUMMARY}

The concept of generic prescription is widely accepted in various parts of the world. Nevertheless, it has failed to gain popularity in India due to factors such as nonavailability and distrust on the product quality. This study was undertaken to evaluate the experience and attitude of patients who were consuming generic drugs purchased from these stores. It was a questionnaire-based cross-sectional study where we have interviewed total 100 patients regarding perceived effectiveness, cost of therapy, quality of drugs. In our study $72 \%$ participants heard about generic medicines and 65\% knew the difference between generic and branded medicines. Most of the patients never asked his/her doctor or pharmacist to prescribe or distribute generic medicines. Majority of them believed that generic medicines have lower quality than branded medicines. Most of them did not become aware of the government rules about prescribing generic medicines. One forth participants responded that government should promote generic medicines. Few patients suggested that there should be more generic medicine shops present in the hospital and they suggested that generic medicines should be available in all medicine shops. Our findings suggest that knowledge and attitude about generic medicines among participants were poor. Some of them had wrong information, which is not a good sign for implementation and sustainability of generic medicine scheme in government hospitals.

\section{REFERENCES}

1. Alfonso-Cristancho $\mathrm{R}$, Andia $\mathrm{T}$, Barbosa T, Watanabe JH. Definition and Classification of Generic Drugs Across the World. Appl Health Econ Health Policy. 2015;13(1):5-11.

2. Thakkar KB, Billa G. The concept of: Generic drugs and patented drugs vs. Brand name drugs and non-proprietary (generic) name drugs. Front Pharmacol [Internet]. 2013;4:113. Available from: http://journal.frontiersin.org/ article/10.3389/fphar.2013.00113/abstract

3. Nguyen TA, Knight R, Roughead EE, Brooks G, Mant A. Policy options for pharmaceutical pricing and purchasing: Issues for low- and middle-income countries. Health Policy Plan. 2014;30(2):267-80.

4. Jennings B, Hastings Center, Editors. Health care quality improvement: Ethical and regulatory issues. Garrison NY: Hastings Center. 2007;4(4):e169.

5. Jan Aushadhi : An Initiative of Government of India | Generic Medicine Campaign Improving Access to Medicines [Internet]. 2018. [cited 2018 Feb 16]. Available from: http://janaushadhi.gov.in/about_jan_aushadhi.html

6. Das M, Choudhury S, Maity S, Hazra A, Pradhan T, Pal A, et al. Generic versus branded medicines: An observational study among patients with chronic diseases attending a public hospital outpatient department. J Nat Sci Biol Med. 2017;8(1):26.

7. Mukherjee K. A Cost Analysis of the Jan Aushadhi Scheme in India. Int J Health Policy Manag. 2017;6(5):253-6.

8. Heikkilä R, Mäntyselkä P, Ahonen R. Do people regard cheaper medicines effective? Population survey on public opinion of generic substitution in Finland. Pharmacoepidemiol Drug Saf. 2011;20(2):185-91.

9. Himmel W, Simmenroth-Nayda A, Niebling W, Ledig T, Jansen RD, Kochen $\mathrm{MM}$, et al. What do primary care patients think about generic drugs? Int $\mathrm{J}$ Clin Pharmacol Ther. 2005;43(10):472-9.

10. Nardi EP, Ferraz MB, Pinheiro GRC, Kowalski SC, Sato El. Perceptions of the population regarding generic drugs in Brazil: A nationwide survey. BMC Public Health. 2015;15(1):117. 